\title{
Eram precisos mais documentários sobre o teatro
}

\section{Daniel Boto}

\author{
Margarida Cardoso, Era preciso fazer as \\ coisas, Filmes do Tejo Il, 2007.
}

\section{Rui Simões, Ensaio sobre o teatro, Real Ficção, 2006.}

Ensaio sobre o teatro seria quase como qualquer outro documentário sobre o erigir de uma peça em palco, não fosse o elevado grau de comprometimento da câmara com aquilo que filma. Estreado no dia 16 de Julho de 2007 no cinema São Jorge em Lisboa, a obra de Rui Simões não tem nada que ver com teatro filmado, já que nem sequer chega a filmar a encenação de Ensaio sobre a cegueira de João Brites na íntegra. Também não é um simples documentário sobre o processo criativo que presidiu à montagem desta peça em particular (que se estreou em 2004 no Teatro Nacional São João, no Porto, para assinalar os 30 anos d'0 Bando), pois não se limita a reconstituir, em vídeo, as várias etapas da sua preparação e execução

Era preciso fazer as coisas também seria quase um documentário sobre a encenação de Nuno Carinhas de 0 tio Vânia, de Tchékhov, não fosse a realizadora/autora Margarida Cardoso tê-lo denominado como filme, o que pressupõe uma qualidade ficcional avessa a essa categoria.

No primeiro caso, trata-se de uma obra de natureza ensaística per se, abordando em profundidade e explorando de forma transversal as alegrias e as dores que subjazem a todas as encenações, enquanto trabalho simultaneamente individual e colectivo, doce e amargo, pleno de satisfação mas também de dúvidas, de desistências, de disputas, de incertezas e de interrogações.

No segundo, a câmara é mais calculista e encenadora, procurando intervir nos processos da criação teatral, construindo a sua actividade narrativa a partir das "vozes interiores" dos intervenientes neste processo. Ao contrário

Pelo apoio recebido para a redacção deste artigo, ficam aqui registados os agradecimentos a Miguel

Jesus (0 Bando) e a

Daniel Boto é mestrando em Arte e Violência na Faculdade de Letras da Universidade de Coimbra. do primeiro, importa-se menos com a mise-en-scène, embora os espaços da representação (Teatro Carlos Alberto, no Porto) ocupem sempre o ecrã.

Ambos partilham um interesse comum: os actores e encenadores enquanto agentes teatrais superando os múltiplos desafios que a teatralização impõe. Nesta matéria, Rui Simões é mais documentarista e mostra estes desafios como parte naturalmente integrante da feitura do espectáculo teatral, que é, no seu estado mais puro, a adaptação dramática de um texto escrito. No caso de Margarida Cardoso, o abismo criado algures neste trajecto que vai da escrita ao palco é cavado com mais gosto, por uma lente mais pungente.

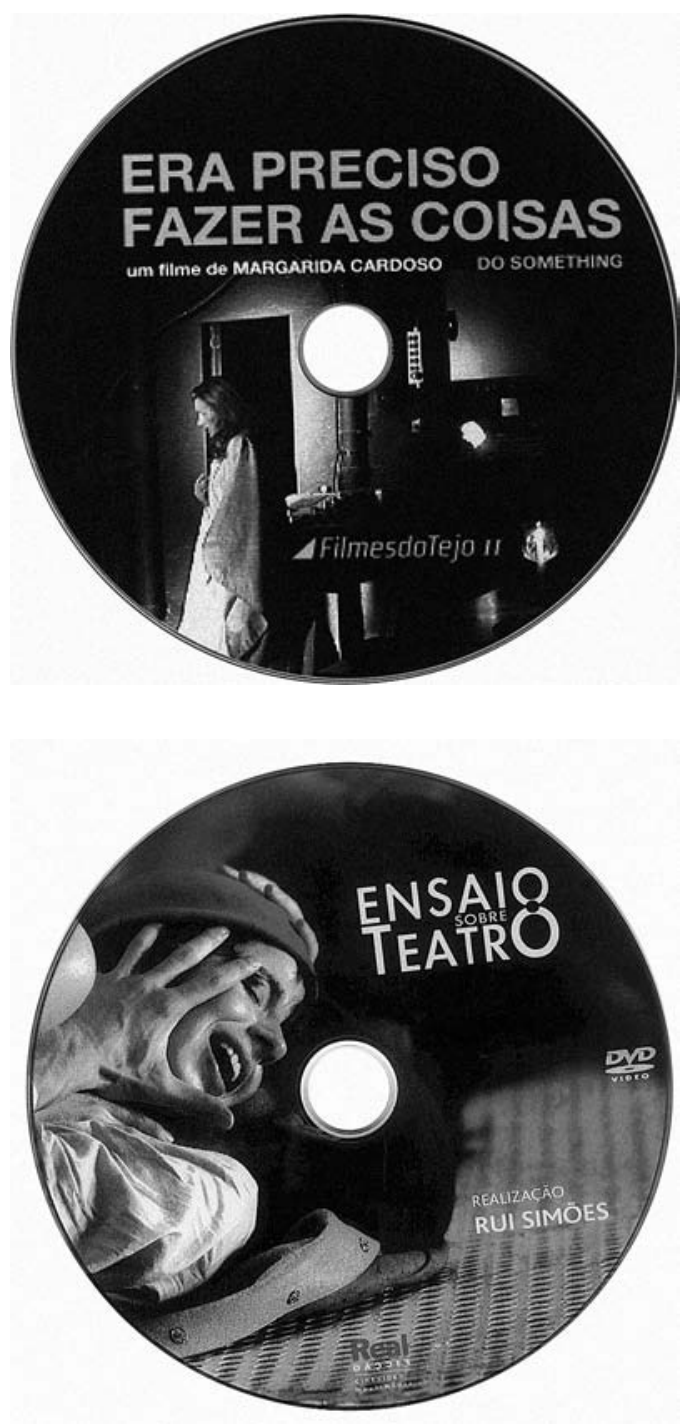

Falar do documentário Ensaio sobre o teatro implicaria falar de Ensaio sobre a cegueira, adaptação teatral, e de Ensaio sobre a cegueira, obra literária. Implicaria, por conseguinte, falar de três autores distintos, unidos por esta obra e apartados pela mesma. A visão de Rui Simões, ocultada sob o kino-olho documentarista que, por natureza, procura abstrair-se daquilo que vê, não é a mesma de João Brites, que procura, por princípio, tornar visivel algo que no seu conjunto não o é, a palavra, e nem a mesma de Saramago, encerrada no insondável e egoísta génio autoral. 


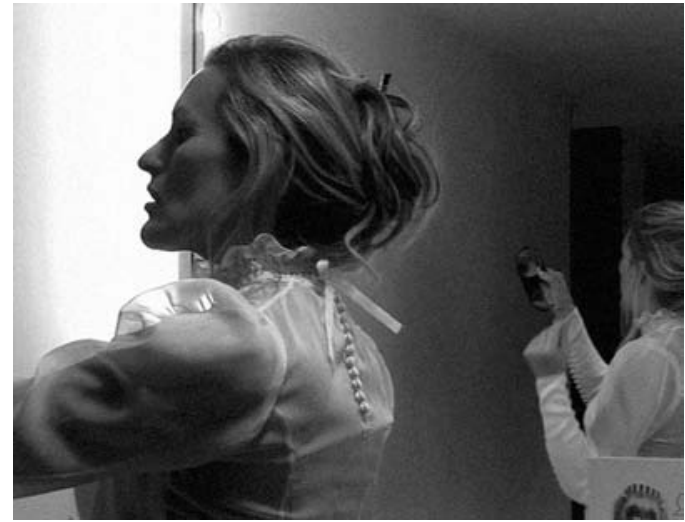

E a grande e esmagadora ironia comum a estas diferentes visões é o facto de todas elas se debruçarem sobre a cegueira. Em todo o caso, a figura do documentarista não ocupa lugar preponderante nem pretende afirmar-se nesta cadeia autoral, limitando-se ao papel de espectador privilegiado que viaja no tempo para nos mostrar o antes e o depois, em constante paralelismo.

Já a visão de Margarida Cardoso é menos inocente, ignorando as artimanhas temporais. Segue em linha recta do princípio ao fim, acompanhando cada momento de dúvida - e mesmo de agonia - até à representação como juízo final, implacável como o tempo directo da cena. Não obstante, mistura o antes da estreia, o muito antes e 0 imediatamente antes. A realizadora não é imparcial, na medida em que parece colocar-se do lado de Tchékhov e dos problemas criados no/pelo texto, mostrando os actores no seu papel de intrusos e de violadores do estranho universo cómico do autor russo que toda a gente teima em considerar trágico. A questão que a realizadora reitera é: por que não nos rimos da fatalidade?

Ensaio sobre o teatro é um título à partida (muito) pretensioso, mas acaba por concretizar inteiramente a ambição de se debruçar sobre as várias componentes da arte da representação, fazendo um autêntico estudo de caso. Se Era preciso fazer as coisas é menos bem sucedido neste aspecto, é porque nem sequer pretende ensaiar sobre coisa nenhuma, muito menos sobre o teatro, embora seja ele, em todo o seu esplendor, a "coisa" que era preciso fazer. Isto é, podia ter sido preciso fazer outra coisa qualquer, o que confere ao filme uma maior liberdade expressiva e criativa - em todos os aspectos.

Ensaio sobre o teatro começa - ou melhor, vai começando - com a câmara que acompanha os actores nos momentos nervosos que antecedem a estreia, ultimando mil e um pormenores. A maquilhagem, os figurinos, as figas e os beijos que se trocam. Os oráculos sucedem-se a espaços, ao fundo do ecrã, baptizando os intervenientes (e revelando um cuidado adicional com a apresentação do produto, técnica que, pelo contrário, não se verifica no trabalho da realizadora). Daqui em diante, o protagonismo passa para o minucioso trabalho de montagem (Márcia Costa), que virá a ser o grande sustentáculo do documentário. Transitamos imediatamente para fora do palco, para onde tudo começou ainda antes de começar; informalmente, os actores aquecem os motores, preparando-os para a intensa viagem de escuridão branca que se há-de seguir. Mais do que criar a personagem de um cego, como se faria num mero exercício de teatro académico, interessa compreender a dimensão da cegueira

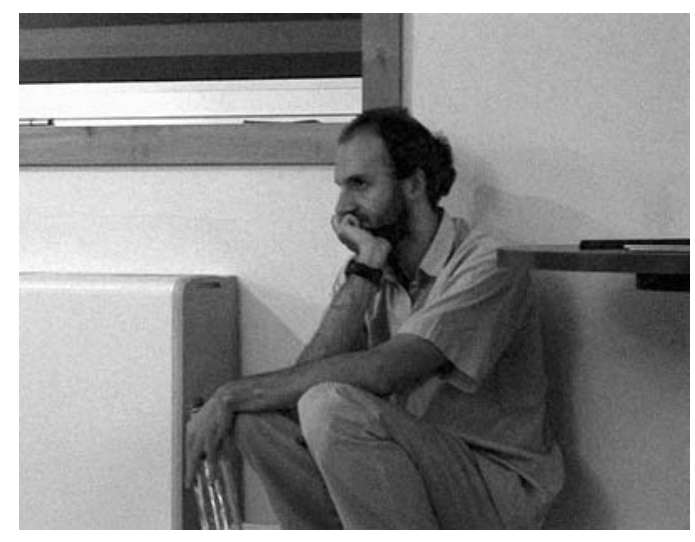

Stills de

Era preciso fazer as coisas, (< Emilia Silvestre; $>$ João Pedro Vaz). no texto, que é uma cequeira de não compreender, diferente da cegueira de não ver.

A câmara caminha em paralelo aos actores nesta tarefa; constrói-se uma cena, por tentativas, e logo a montagem milimetricamente encadeada nos mostra como foi o efeito final em palco, fazendo a transição imediata entre a experiência e o resultado.

Este paralelismo constante, para além de economizar do ponto de vista narrativo, acrescenta interesse na medida em que permite ao espectador inteirar-se da diversidade de processos que estão implicados numa encenação séria. Neste aspecto, assistimos ao registo em vídeo puramente documental da construção da peça, que simultaneamente a engrandece e a desmascara.

Mas o filme opera uma outra "revelação": a do trabalho prévio de experimentação dos actores com vista à construção de uma corporalidade adequada (assinada por Luca Aprea), que foi moroso mas fundamental. Deslocar um grupo numeroso de actores para fora, em regime semelhante ao de residência artística e com tudo o que isso implica, para ver com os dedos o espaço em volta e tentar uma aproximação com o ambiente dantesco do livro, é algo que requer uma grande entrega, entusiasmo e perseverança por parte de todos. Mesmo se falamos de um grupo de profissionais, o desafio de adaptar para teatro um livro como este, aparentemente mais favorável a apropriações cinematográficas (problema que cabe ao encenador resolver), adivinha-se grande. Mas, como se verifica, todos intervêm num imenso, rigoroso e por vezes lento processo de criação de uma autêntica persona, trabalhando-se inclusive pormenores como a voz, que se esforça por encontrar um registo quase inverosímil para nele se manter.

Seleccionado para o primeiro Festival de Lisboa do Cinema Ibérico (Hola Lisboa), Famafest 2007 e Festival Cinesul 2007 (Brasil), o filme capta o carácter experimental inerente à construção e montagem da peça. Sendo um ensaio sobre o teatro, é também um ensaio sobre o actor e o seu trabalho. Os 90 minutos de filme captam, no seu conjunto, muito mais que as três horas de peça; o DVD vem também munido de "Recordações do Hospital Velho" (em Viseu), espaço onde os actores operaram a sua preparação. Falando de extras (e porque convém mostrar mais do que um ponto de vista, tratando-se de um ensaio), figuram igualmente entrevistas ao escritor e ao encenador. Quanto à visão do realizador, ela manifesta-se, como um texto, na montagem.

Noutro plano, a música parece ter conduzido igualmente a montagem do documentário; na verdade, 
cento e dezasseis

Sinais de cena 9. $2008 \quad$ Leituras

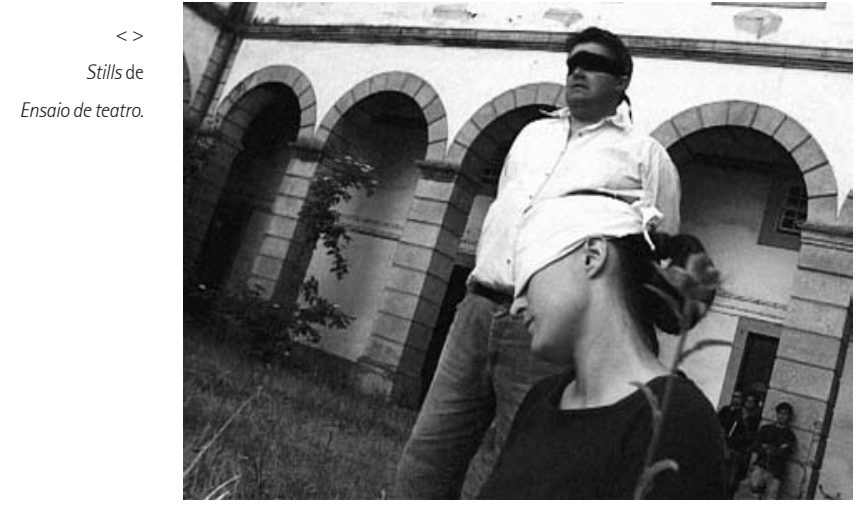

este ensaio sobre o teatro é também um ensaio sobre a música no teatro.

Outro distintivo deste documentário, que o torna ensaísta e não meramente uma câmara narradora, é a sua atitude indiscreta; ela flagra os actores nos seus momentos sem máscaras, denunciando a sua difícil relação com as personagens e com o palco, o que, apesar de tudo, constitui um desafio aliciante. Este efeito contribui para a erradicação definitiva da quarta parede, se é que resta alguma depois desta encenação tão vivida e tão próxima do público. Se, por um lado, o objectivo é que todos tomemos consciência da nossa cegueira, por outro, o filme não esconde o processo de (dis)simulação que é o teatro, de construção de uma realidade falsa e artificiosa pelo actor que, à semelhança do poeta pessoano, não passa de um fingidor, querendo enganar um público cego.

No documentário, como na peça e como no livro, existe uma força positiva oculta por detrás de tanta negrura, cegueira, nudez, frieza e violência. Existe o Amor, essa noção abstracta que tudo redime e absolve, e que não permite que esta obra, independentemente da sua forma, seja totalmente negra. Trágica, sim, mas luminosa. Afinal, "os olhos não são mais que duas lentes, duas objectivas. 0 cérebro é que realmente vê". Por outras palavras, este documentário não é mais que uma lente que torna visivel a ilusão teatral.

Em Era preciso fazer as coisas, a exploração da vertente de dissimulação no teatro surge como consequência de um interesse maior, que é o de captar o genuíno intuito do actor em se aproximar da sua personagem. Fazer uma leitura dela, conseguir chegar-lhe, é por si só tarefa dramática. A luta pelo despojamento interior, que permitirá encaixar no eu-actor o eu-personagem, é o tema principal do filme. Para atingir este objectivo, Margarida Cardoso pediu aos actores que falassem na primeira pessoa sobre

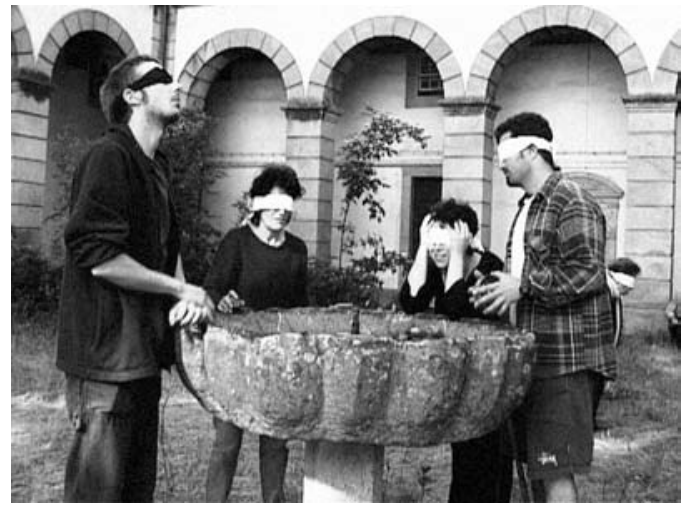

as suas dificuldades, as suas expectativas e os seus medos. Vemo-los (leia-se: ouvimo-los) confessar os seus percursos de vida individuais e apercebemo-nos de que os actores são afinal pessoas como nós, talvez apenas mais corajosos e obstinados, querendo chegar ao texto e ao palco, lutando contra uma omnipresente pulsão que os impele a desistir perante as adversidades e o medo de falhar, de não estar à altura da personagem, de comprometer-se a si e ao "outro".

Querendo mostrar-nos aquilo que foi a preparação da encenação da peça de Tchékhov, por Nuno Carinhas, este filme, premiado na última edição do Festival Doclisboa (Grande prémio Tobis para melhor filme português de longa-metragem e Prémio Midas para melhor filme português presente no festival), excede completamente a aparente valência de making of. Ademais, nem sequer chegamos a ver a encenação final. Trata-se de um exercício puramente cinematográfico, com linguagem própria, que nada tem a ver com teatro.

Em suma, os dois documentários partem de uma mesma realidade - a montagem de uma peça de teatro - embora sobre ela se debrucem sob diferentes perspectivas; uma mais formal, mais documental e mais generalista, a outra mais cinematográfica, assumidamente mais autoral e menos comprometida com o que filma. Em comum têm a inegável habilidade para gerar interesse em torno da actividade teatral, dignificando o trabalho e a persona dos seus agentes, contribuindo para o envolvimento do público em geral com as artes do palco. A participação financeira de entidades públicas revela que são sensiveis a esta necessidade de (re)conciliação do público português com o teatro (em) português. Faltaria talvez que as televisões também reconhecessem a importância destes trabalhos. E, sem dúvida, era preciso mais ensaios como estes. 